\title{
Numerical Calculation of Tooth Profile of a Non-circular Curved Face Gear
}

\author{
Chao Lin* - Dong Zeng - Xianglu Zhao - Xijun Cao \\ Chongqing University, The State Key Laboratory of Mechanical Transmission, China
}

Based on the cylindrical coordinates and the space engagement theory, which utilize a cylindrical coordinate system, an arbitrary curve equation was obtained and a method of curve expansion was established. This allows any order of pitch curve of non-circular curved face gear and normal equidistant curve parameter equations to be derived. The tooth profile points of the non-circular curved face gear can be solved using the numerical calculation method where the tooth profile intersects with the pitch curve and normal equidistant curves of non-circular curved face gear. Finally the numerical method used to solve the tooth profile of the non-circular curved face gear was proved to be accurate and correct from the small error between measured data and the data of theoretical calculation.

Keywords: non-circular curved face gear, cylindrical coordinates, pitch curve, numerical calculation of tooth profile, error analysis

Highlights

- $\quad$ Built a mathematical model and a expansion method of an arbitrary curve.

- $\quad$ Derived equations of the pitch curve and the normal equidistant curves of the non-circular curved face gear.

- $\quad$ Proposed a numerical method to calculate the tooth profile.

- Measured the tooth profile and analyzed the error of the tooth profile to verify the numerical method.

\section{INTRODUCTION}

The non-circular curved face gear drive is also called the orthogonal variable transmission ratio face gear drive. It is generated by replacing the spur pinion and its conjugated face gear of a conventional face gear drive by a non-circular gear and its conjugated face gear [1]. The transmission ratio is variable when the non-circular curved face gear engages with non-circular gear, since the teeth distributed on the cylindrical surface. This is the most significant feature compared to the conventional face gear. This type of gear drive has many possible applications in the field of engineering, textile, agriculture, etc.

In 1940, Buckingham came up with the concept of the face gear in the paper [2], which he defined as a rack of changing tooth pitch and pressure angles; Litvin and his team made a strong contribution to the research about face gears on the basis of their predecessors' research. His book [3] gave in-depth research about the surface of the face gear in terms of the gear geometry and meshing principle; Ji et al and Zhu et al. did a lot of research on face gears in the field of tooth surface contact analysis, strength, coincidence degree theory, etc. [4]; Lin et al. were the first to propose a non-circular curved face gear and explored its tooth profile analysis, machining simulation, measurement, etc. and this study made significant achievements. To date there has been little research about the tooth profile of non-circular curved face gears [5] and [6].

The error of the tooth profile will not only impact on the instantaneous transmission accuracy but also cause plastic deformation on the tooth surface of intermeshing gear. There exist some methods for using the numerical method to solve the gear tooth profile, for instance, Xia et al., Li et al. and Tong et al. calculated the tooth profile of a bevel gear using the numerical method which was based on the spherical coordinates [7] to [9]. In the field of gear measurement, Guenther et al. and Zhang et al. put forward some new theories and methods of measuring and analyzing gears [10] to [12]. But, at present, there is no practical way of using the numerical method to solve the tooth profile of non-circular curved face gear. This paper presents a new general numerical method used to calculate the tooth profile of a non-circular curved face gear. This method will serve as an important reference basis in the field of modeling, processing, analyzing errors of measurement, and so forth.

\section{PARAMETERS OF THE CURVE IN THE CYLINDRICAL COORDINATE SYSTEM}

The non-circular curved face gear is a kind of cylindrical gear. In order to describe and calculate the parameters of the gear more accurately, this paper prepared a study of the angle and the expansion of the curve under the cylindrical coordinate system. 


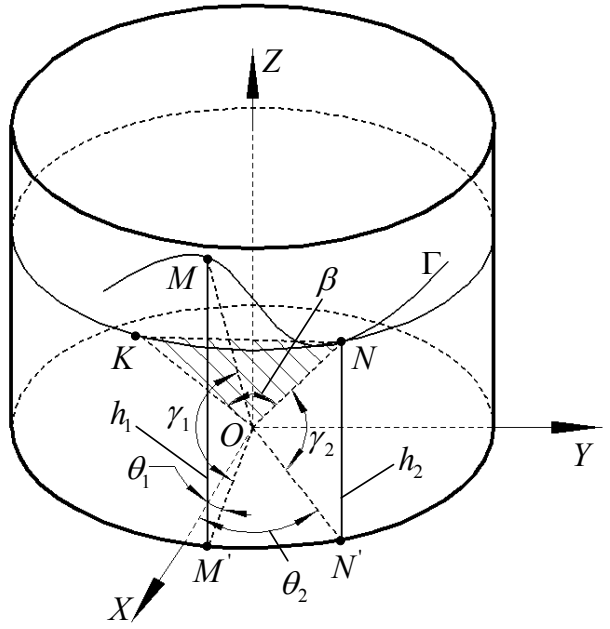

Fig. 1. Parameters of the curve in the cylindrical coordinate system

As shown in Fig. 1, $O-X Y Z$ is the cylindrical coordinate system, $\Gamma$ is one curve on the cylindrical surface, $M$ and $N$ are any two points on the curve. $\theta$ is the rotation angle which is from the positive $X$ axis to the point. $h$ is the distance between the point and the bottom surface, $\gamma$ is the central angle of the point on the curve, $R$ is the cylindrical radius.

\subsection{Basic Description of the Curve}

Assume that the equation of any curve is:

$$
\Gamma=\left(\begin{array}{lll}
R \cos \theta & R \sin \theta & h(\theta)
\end{array}\right) .
$$

The arc length between points $M$ and $N$ is:

$$
L_{\overparen{M N}}=\int_{\theta_{1}}^{\theta_{2}} \sqrt{R^{2}+h^{\prime 2}(\theta)} d \theta,
$$

where $h^{\prime}(\theta)$ is the derivative of $h(\theta)$.

The central angle of one point on the curve can be defined as the angle between the line which links that point to the center of the circle in the bottom surface and the bottom surface. According to the geometric relationship the formula is:

$$
\gamma=\arctan \frac{h(\theta)}{R} .
$$

\subsection{Expansion of the Curve}

The line linking all points on the curve to the center of the circle in the bottom surface will compose a conical surface. As shown in Fig. 1, there are countless tangent planes through point $N$. However, there exists a unique tangent plane that is vertical to the $Z$ axis. There exists one point $K$ on the line intersected by the tangent plane and the cylindrical surface where $L_{\overparen{M N}}=L_{\overparen{N K}}$. At the same time the plane $O K N$ is an expansion of the plane $O M N$. To solve Eq. (2), we get:

$$
L_{\overparen{N K}}=L_{\overparen{M N}}=\int_{\theta_{1}}^{\theta_{2}} \sqrt{R^{2}+h^{\prime 2}(\theta)} d \theta .
$$

Thus the expansion angle $\beta$ corresponding to the curve $M N$ is:

$$
\beta=\frac{1}{\sqrt{R^{2}+h^{2}(\theta)}} \int_{\theta_{1}}^{\theta_{2}} \sqrt{R^{2}+h^{\prime 2}(\theta)} d \theta .
$$

\section{PITCH CURVE OF THE NON-CIRCULAR CURVED FACE GEAR}

\subsection{Equation of the Pitch Curve}

According to the meshing relationship of the noncircular curved face gear pair, a coordinate system can be established.

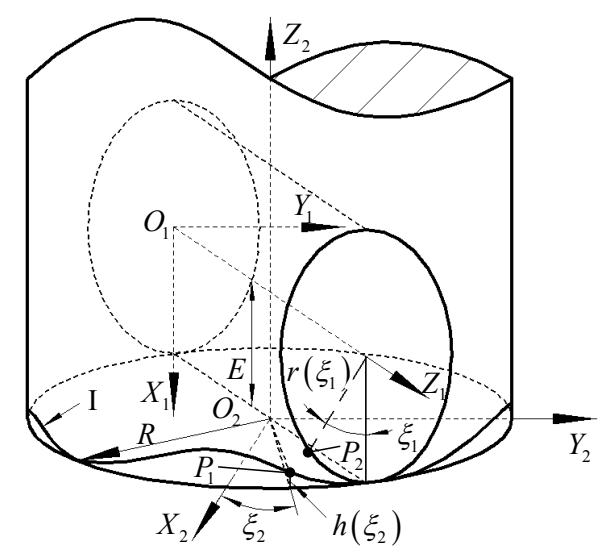

Fig. 2. Meshing coordinate of the non-circular curved face gear

As shown in Fig. 2, the axis of the non-circular gear is orthogonal to axis of the non-circular curved face gear. As shown in Fig. 2, $O_{1}-X_{1} Y_{1} Z_{1}$ is the fixed coordinate system of the non-circular gear. $\mathrm{O}_{2}-X_{2} Y_{2} Z_{2}$ is the fixed coordinate system of the noncircular curved face gear. The point $P_{1}$ is on the pitch curve of non-circular gear and the point $P_{2}$ is on the pitch curve of non-circular curved face gear. When $P_{1}$ coincides with $P_{2}$, the non-circular gear turns at an angle of $\xi_{1}$, and the non-circular curved face gear turns at an angle of $\xi_{2}$. The radius of the pitch curve of the non-circular curved face gear is $R$, and the radius vector of the non-circular gear is $r\left(\xi_{1}\right)$. Under the conditions of Fig. 2, the distance between the axis of the non-circular gear and the bottom surface of 
the face gear is $E$. I is the pitch curve of non-circular curved face gear.

According to the theory of non-circular gears, the equation for the pitch curve of the non-circular gear is:

$$
r\left(\xi_{1}\right)=\frac{a\left(1-e^{2}\right)}{1-e \cos \left(n_{1} \xi_{1}\right)},
$$

where, $\xi_{1}$ is the polar angle of the elliptic gear, $a$ is half of the longer axis of the ellipse, $e$ is the eccentricity of the ellipse, $n_{1}$ is the order of the non-circular gear.

When the parameters in Eq. (6) were chosen as follows: $a=35 \mathrm{~mm}, e=0.1$ and $n_{1}$ changes from 1 to 4 . The pitch curve of the non-circular gear can be shown in Fig. 3.
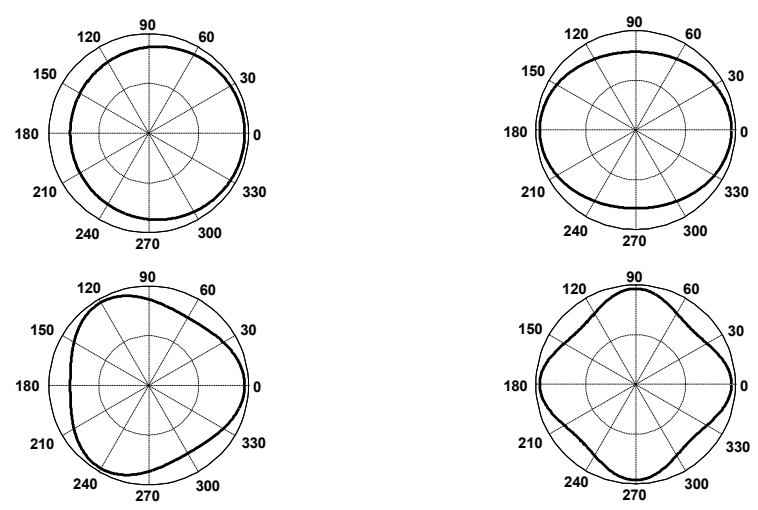

Fig. 3. Impact of $n_{1}$ on the pitch curve of the non-circular gear

In the meshing process of the non-circular gear and non-circular curved face gear, the center distance is fixed. From the geometric relationship shown in Fig. 2, Eq. (7) is correct at any point in time.

$$
E=h\left(\xi_{2}\right)+r\left(\xi_{1}\right)=a+a e,
$$

where, $h\left(\xi_{2}\right)$ is the distance between the point on the pitch curve and the bottom surface when the noncircular face gear turns an angle $\xi_{2}$.

By substituting Eq. (6) and Eq. (7) into Eq. (1), the pitch curve of the non-circular curved face gear can be obtained.

$$
r_{2}=\left\{\begin{array}{c}
x=R \cos \xi_{2} \\
y=R \sin \xi_{2} \\
z=h\left(\xi_{2}\right)=E-r\left(\xi_{1}\right)
\end{array},\right.
$$

where,

$$
R=\frac{n_{2}}{2 \pi} \int_{0}^{\frac{2 \pi}{n_{1}}} r(\xi) d \xi, \quad \xi_{2}=\int_{0}^{\xi_{1}} \frac{1}{i_{12}} d \xi=\frac{1}{R} \int_{0}^{\xi_{1}} r(\xi) d \xi,
$$

$n_{1}$ is the order of the non-circular gear, $n_{2}$ is the order of non-circular curved face gear, $i_{12}$ is the transmission ratio of the non-circular curved face gear pair and $i_{12}=$ $\mathrm{R} / r\left(\xi_{1}\right)$.

By substituting the equations above into Eq. (8), the pitch curve of the non-circular curved face gear can be obtained.

$$
r_{2}\left(\xi_{2}\right)=\left\{\begin{array}{c}
x=\frac{n_{2}}{2 \pi} \cos \xi_{2} \int_{0}^{\frac{2 \pi}{n_{1}}} r(\xi) d \xi \\
y=\frac{n_{2}}{2 \pi} \sin \xi_{2} \int_{0}^{\frac{2 \pi}{n_{1}}} r(\xi) d \xi . \\
z=h\left(\xi_{2}\right)=E-r\left(\xi_{1}\right)
\end{array}\right.
$$

\subsection{Tooth Modulus Angle of the Pitch Curve Plane}

As shown in Fig. 4, based on the method of the expansion of the curve, tooth 1 and tooth 2 represent any 2 teeth on the pitch curve of the non-circular curved face gear. Point $M$ and point $N$ are the points on the right tooth profile of tooth 1 and tooth 2 . There is a complete tooth profile between $M$ and $N$. By expanding the tooth profile on the tangential circle of the pitch curve, the point $K$ on the tangential circle can be obtained. When the arc length of $\overparen{M N}$ is equal to $\widetilde{K N}$, the plane $O K N$ is the expansion plane of the one tooth profile.

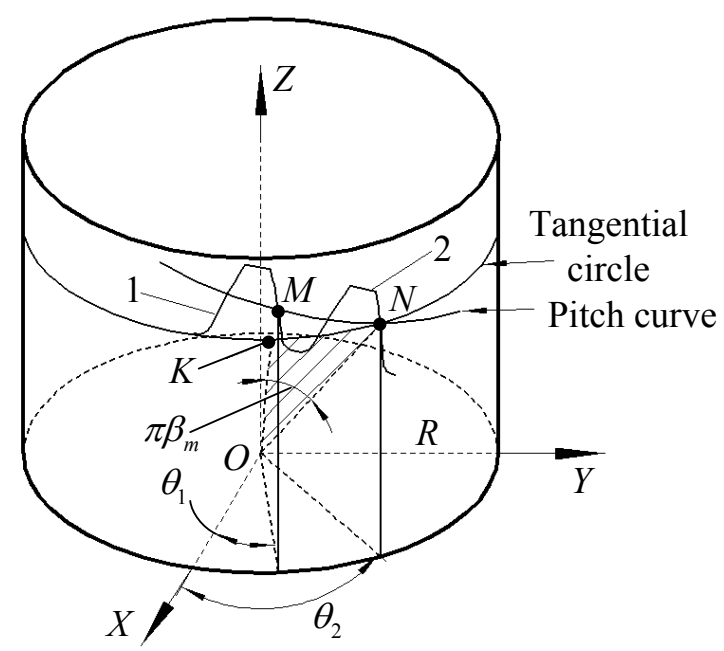

Fig. 4. Tooth modulus angle of the non-circular curved face gear

When the angle $\beta=\pi \beta_{m}, \beta_{m}$ is the modulus angle of the tooth. The tooth profile of the non-circular curved face gear changes when the direction of the tooth width changes and so does the modulus angle. 


\subsection{Addendum Angle and Dedendum Angle}

As shown in Fig. 5, the addendum line, pitch curve and dedendum line of the non-circular curved face gear are on the cylindrical surface $\Pi$. The tangential plane through the center point $O$ of the bottom surface intersects with the addendum line, pitch curve and dedendum line at points $M, P$ and $N . M N$ is the tangent section on the cylindrical surface. Angles $M O P$ and $P O N$ are defined as the addendum angle and the dedendum angle. And,

$$
\left\{\begin{array}{c}
\alpha_{a}=h_{a}^{*} \cdot \beta_{m} \\
\alpha_{f}=\left(h_{a}^{*}+c^{*}\right) \beta_{m}
\end{array},\right.
$$

where, $h_{a}^{*}$ is the addendum coefficient, $c^{*}$ is the dedendum coefficient. $\beta_{m}$ is the modulus angle.

So the addendum and dedendum of the noncircular curved face gear are:

$$
\left\{\begin{array}{l}
h_{a}=R \tan \left(\gamma+\alpha_{a}\right) \cdot h\left(\xi_{2}\right) \\
h_{f}=R \tan \left(\gamma-\alpha_{f}\right) \cdot h\left(\xi_{2}\right)
\end{array}\right.
$$

where, $\gamma$ is the center angle, $R$ is the radius of the pitch curve of non-circular curved face gear, $\alpha_{a}$ is the addendum angle of non-circular curved face gear, and $\alpha_{f}$ is the dedendum angle of non-circular curved face gear.

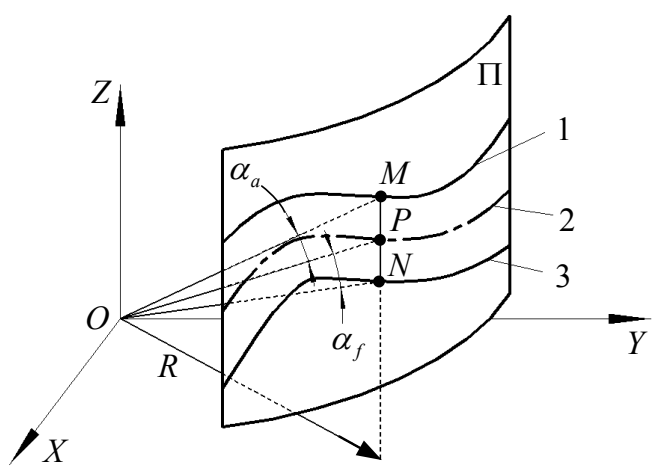

Fig. 5. Addendum angle and dedendum angle (1 addendum line, 2 pitch curve, and 3 dedendum line)

\section{USING THE NUMERICAL METHOD TO SOLVE TOOTH PROFILE}

The fundamental theory of the numerical method in solving the tooth profile of non-circular curved face gear is derived from the generating process of the noncircular curved face gear. The generating process is shown in Fig. 6.

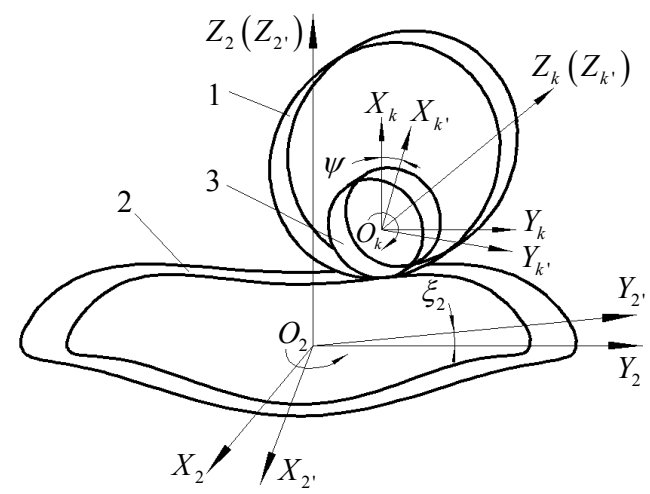

Fig. 6. Coordinate system of generating process

As shown in Fig. $6, O_{k}-X_{k} Y_{k} Z_{k}$ is rigidly connected to the frame of the cutting machine. $O_{k^{\prime}}-X_{k^{\prime}} Y_{k^{\prime}} Z_{k^{\prime}}$ is rigidly connected to the cutter. Likewise $\mathrm{O}_{2}-X_{2} Y_{2} Z_{2}$ is rigidly connected to the frame of the cutting machine. $O_{2},-X_{2}, Y_{2}, Z_{2}$, is rigidly connected to the non-circular curved face gear.

According to the principle of gear engagement, the transformation matrix from $X_{k k^{\prime}}$ to $M_{22}$ can be derived as:

$$
\begin{gathered}
M_{2^{\prime} k^{\prime}}=M_{2^{\prime} 2} M_{2 k} M_{k k^{\prime}}= \\
=\left[\begin{array}{cccc}
\sin \psi \sin \xi_{2} & \cos \psi \sin \xi_{2} & -\cos \xi_{2} & R \cos \xi_{2} \\
\sin \psi \cos \xi_{2} & \cos \psi \cos \xi_{2} & \sin \xi_{2} & -R \sin \xi_{2} \\
\cos \psi & -\sin \psi & 0 & h\left(\xi_{2}\right) \\
0 & 0 & 0 & 1
\end{array}\right],
\end{gathered}
$$

where, $\psi$ is the rotating angle of cutter when the noncircular curved face gear rotates at an angle of $\xi_{2}$.

The rotation angle of the cutter can be obtained from the processing geometric relationships.

$$
\begin{aligned}
\psi= & \frac{\pi}{2}-\xi_{1}-\arctan \left(\frac{r\left(\xi_{1}\right)}{r^{\prime}\left(\xi_{1}\right)}\right)+ \\
+ & \frac{\int_{0}^{\xi_{1}} \sqrt{r^{2}(\xi)+r^{\prime 2}(\xi)} d \xi}{r_{k}},
\end{aligned}
$$

where $r^{\prime}(\xi)$ is the derivative of $r(\xi)$ and $r_{k}$ is the radius of the pitch curve of cutter gear.

\subsection{Equation of the Equidistant Curve of the Pitch Curve}

The equation of the normal equidistant curve can be derived from the pitch curve equation of the noncircular curved face gear.

In Fig. 7, curves 1, 2, 3 stand for the expansion of addendum line, pitch curve and dedendum line of a non-circular curved face gear, respectively. $P_{a}$ is the intersection of the addendum line and the normal line 
of the pitch curve through point $P . P_{f}$ is the intersection of the dedendum line and the normal line of the pitch curve through point $P . \eta$ is the angle of the normal and vertical direction and therefore $\eta$ can be expressed as:

$$
\eta=\arctan \left(\frac{e n_{1} \sin \left(n_{1} \xi_{1}\right)}{1-e n_{1} \cos \left(n_{1} \xi_{1}\right)}\right) .
$$

Assuming that there are $n$ normal equidistant curves between the addendum line and the dedendum line. The parametric equations of $n / 2$ equidistant curves from the pitch curve to the addendum line and another $n / 2$ equidistant curves from the dedendum line to the pitch curve can be derived from Eq. (9).

$$
\begin{gathered}
\left\{\begin{array}{c}
x_{1}=R \cos \left(\xi_{2}-\frac{2 t_{1} h_{a} \sin \eta}{n R}\right) \\
y_{1}=R \sin \left(\xi_{2}-\frac{2 t_{1} h_{a} \sin \eta}{n R}\right), \\
z_{1}=h\left(\xi_{2}\right)+\frac{2 t_{1} h_{a}}{n} \cos \eta
\end{array}\right. \\
\left\{\begin{array}{c}
x_{2}=R \cos \left(\xi_{2}-\frac{2 t_{2} h_{f} \sin \eta}{n R}\right) \\
y_{2}=R \sin \left(\xi_{2}-\frac{2 t_{2} h_{f} \sin \eta}{n R}\right), \\
z_{2}=h\left(\xi_{2}\right)+\frac{2 t_{2} h_{f}}{n} \cos \eta
\end{array}\right.
\end{gathered}
$$

where, $n$ is the number of the normal equidistant curves. The $t_{1}$ and $t_{2}$ represent respectively the $t_{1}-t h$ equidistant curve from the pitch curve to addendum line and the $t_{2}-t h$ equidistant curve from the pitch curve to dedendum line respectively. When $t_{1}=n / 2$, it is the addendum line. When $t_{2}=n / 2$, it is the dedendum line.

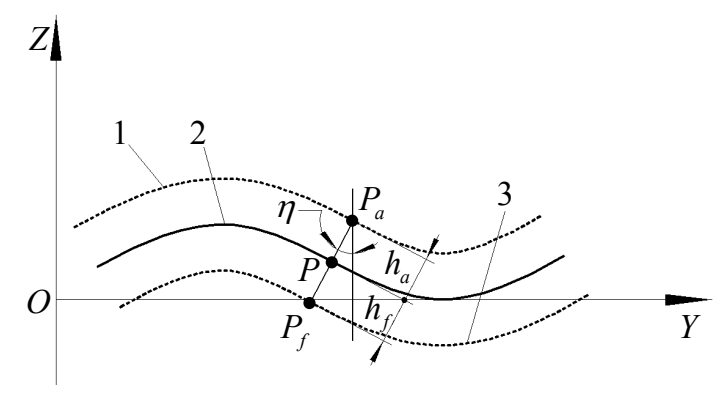

Fig. 7. Planimetric pitch curve of non-circular curved face gear

\subsection{Using the Numerical Method to Solve the Tooth Profile}

The tooth profile of the non-circular curved face gear can be derived by building the equation of the normal equidistant curve of the non-circular curved face gear using the method above. During the process, the intersection is at a given point if it satisfies the engagement conditions when the cylindrical cutter tooth profile associates with the equidistant curve of the pitch curve of the non-circular curved face gear.

According to mechanical principles, the tooth profile equation of an involute cylindrical gear cutter is [13]:

$$
\left\{\begin{array}{c}
x_{k}= \pm r_{b}\left[\sin \left(\theta_{k o}+\theta_{k}\right)-\theta_{k} \cos \left(\theta_{k o}+\theta_{k}\right)\right] \\
y_{k}=-r_{b}\left[\cos \left(\theta_{k o}+\theta_{k}\right)+\theta_{k} \sin \left(\theta_{k o}+\theta_{k}\right)\right] \\
z_{k}=u_{k}
\end{array}\right.
$$

where \pm stands for left or right tooth profile of the cutter gear. $r_{b}$ is the radius of the base circle, $\theta_{k}$ is the angle of any point on the involute, $\theta_{k o}$ is the angle from the involute-starting point to the center line of the gullet, $\theta_{k o}=\pi / 2 z+i n v \alpha_{k}, u_{k}$ is the parameter in the direction of tooth width and $\alpha_{k}$ is the pressure angle of the cutter gear.

When $u_{k}$ is determined, the tooth profile of the cutter gear can be calculated by the software of Matlab. According to the coordinate transformation equation $P 2^{\prime}=M_{2^{\prime} k^{\prime}} P k^{\prime}$, the tooth profile of the cutter gear is transferred to the following coordinates of the non-circular curved face gear. Thus, the intersections are calculated through the equations of the line of the points obtained above and the equidistant curve equation of the pitch curve of the non-circular curved face gear.

As shown in Fig. 8a, the left tooth profile of the cutter has four points, which equidistant from one another. $P_{1}^{2^{\prime}}, P_{2}^{2^{\prime}}, P_{3}^{2^{\prime}}, P_{4}^{2^{\prime}}$ are obtained by transforming the points to the coordinates $O_{2^{\prime}}-X_{2^{\prime}}, Y_{2^{\prime}} Z_{2^{\prime}}$. Three lines can be obtained by linking the adjacent points. Intersections are calculated though the equations of the lines and equidistant curves.

The gear pair can be obtained through generating process. There also exist intersection points where the tooth profile of the cutter intersects with equidistant curves when the tooth space is processed. These points of tooth profile can be verified using the meshing condition. According to the principle of gear engagement, the points of the tooth profile of the noncircular curved face gear must satisfy the meshing 
equation. So the intersection points obtained above should satisfy the meshing equation [1]:

$$
\begin{gathered}
\vec{N} \cdot \vec{v}_{2 k}= \\
=r_{b}+\cos (\zeta-\lambda) \sqrt{r^{2}\left(\xi_{1}\right)+r_{k}^{2}-2 r_{k} r\left(\xi_{1}\right) \sin \mu}- \\
-i_{21}\left(R+u_{k}\right) \cos \zeta=0,
\end{gathered}
$$

where $\vec{N}$ stands for the normal line of cutter tooth surface and $\vec{v}_{2 k}$ stands for the relative velocity of the cutter and the non-circular curved face gear. These two parameters need to be expressed in the same coordinate system. As shown in Fig. $8 \mathrm{~b} r_{b}=r_{k} \cos \alpha_{k}$ and $\zeta=\psi+\xi_{1}-\theta_{k}-\theta_{k o}$.

Finally the points that satisfy Eq. (18) are on the tooth profile.

Tooth profile of cutter
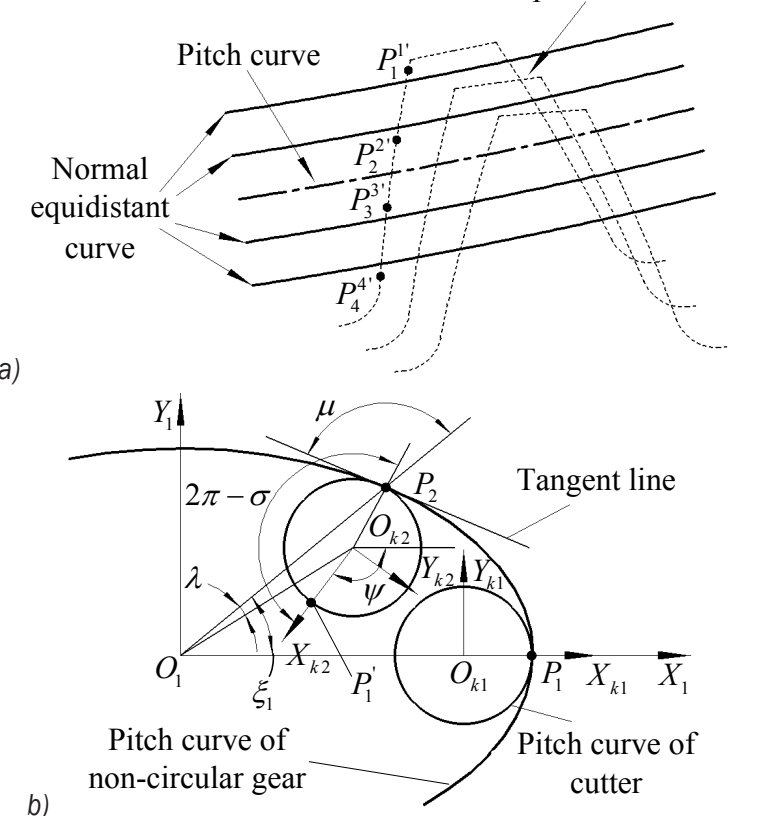

Fig. 8. Numerical method for solving the tooth profile; a) intersection of the tooth profile and normal equidistant curves and b) space location of the gear shaper cutter

\subsection{Examples of Calculation}

The 4-order non-circular curved face gear is processed using an involute cylindrical gear cutter where the parameters are the tooth number $z=12$, the pressure angle $\alpha_{k}=20^{\circ}$, and the module $m=4$. The gear pair is shown in Fig. 9.

As shown in Fig. 10a, according to the principle of using the numerical method to solve the tooth profile [10] to [12], the $u_{k}$ is divided in accordance with a tooth width of $72.5 \mathrm{~mm}, 74.5 \mathrm{~mm}, 76.5 \mathrm{~mm}, 78.5$ $\mathrm{mm}, 80.5 \mathrm{~mm}$. 5 equidistant curves used to divide the tooth are distributed $1.5 \mathrm{~mm}$ from one another along the tooth depth direction. The middle one of the 5 curves is coincide with the pitch curve.

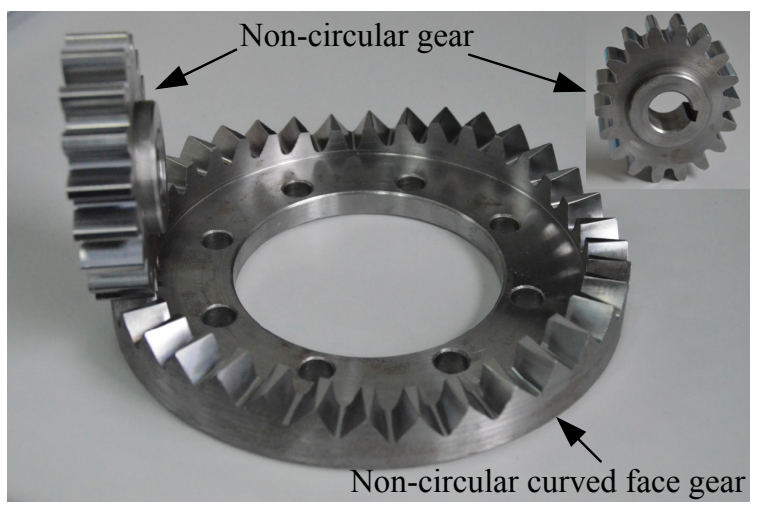

Fig. 9. Material object of non-circular curved face gear

Here we calculate the coordinate value of the left tooth surface of tooth 1 . The results of the mesh generation are shown in Fig. 10b. The coordinate values are shown in Table 1.

a)

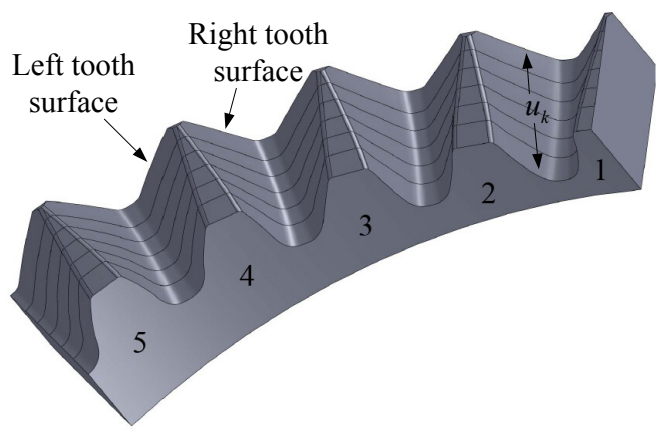

b)

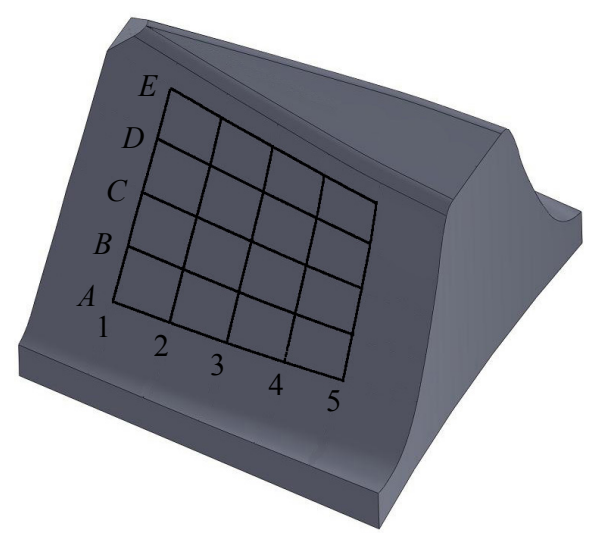

Fig. 10. Division of measurement grids; a) mesh generation of tooth depth direction, and b) node number on tooth 1 
Table 1. Coordinate values of theoretical points on the left surface of tooth 1 in [ $\mathrm{mm}]$

\begin{tabular}{cccc}
\hline & 1 & 3 & 5 \\
\hline \multirow{3}{*}{$\mathrm{E}$} & -80.49168, & -76.48175, & -72.46920, \\
& -1.13698, & -1.66847, & -2.11100, \\
& 3 & 3 & 3 \\
\hline \multirow{2}{*}{$\mathrm{C}$} & -80.43873, & -76.43156, & -72.42771, \\
& -3.14385, & -3.23707, & -3.23691, \\
& 0 & 0 & 0 \\
\hline \multirow{2}{*}{$\mathrm{A}$} & -80.32150, & -76.32929, & -72.34882, \\
& -5.35782, & -5.10585, & $-4.67954,-$ \\
& -3 & -3 & 3 \\
\hline
\end{tabular}

\subsection{Measurement of Non-Circular Curved Surface Gears}

As shown in Fig. 11, the non-circular curved face gear was measured by the contour scanning software of a German Klingelnberg P26 automatic CNC controlled gear measuring center. Since each tooth profile in one cycle on the gear is different, contour scanning should be used as the measuring.

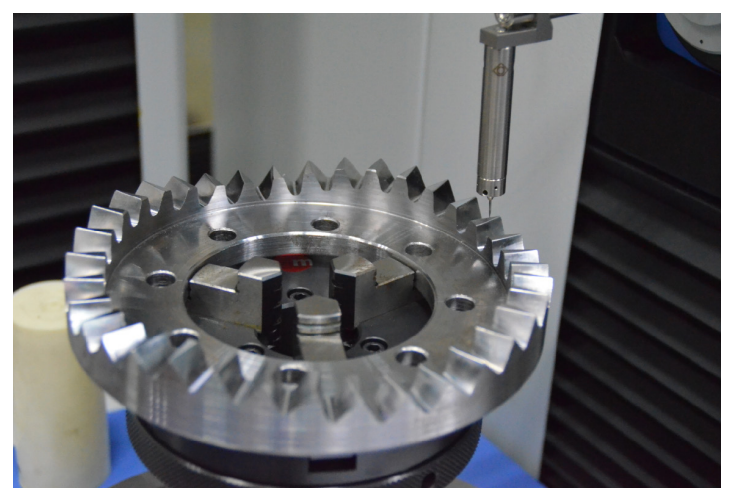

Fig. 11. Profile measurement of the non-circular curved face gear

Table 2. Coordinate values of the measured points on the left surface of tooth 1 in [mm]

\begin{tabular}{cccc}
\hline & 1 & 3 & 5 \\
\hline \multirow{3}{*}{$\mathrm{E}$} & -80.477, & -76.484, & -72.459, \\
& -1.138, & -1.661, & -2.105, \\
& 3 & 3 & 3 \\
\hline \multirow{3}{*}{$\mathrm{C}$} & -80.441, & -76.434, & -72.419, \\
& -3.132, & -3.224, & -3.227, \\
& 0 & 0 & 0 \\
\hline \multirow{3}{*}{$\mathrm{A}$} & -80.323, & -76.323, & -72.349, \\
& -5.369, & -5.106, & -4.667, \\
& -3 & -3 & -3 \\
\hline
\end{tabular}

According to the measurement and theoretical calculation process, the radius of tooth width, which is the motion trajectory of the probe, is the same as the one calculated above. The coordinate values of the grid nodes on the left tooth surface of tooth 1 are obtained using the measurement points from the neighboring space of the theoretical point from the measured data. The specific values are shown in Table 2.

\subsection{Error Analysis of the Tooth Profile}

Since there are errors in the actual processing, measurement and in the precision of the numerical method, there also exist errors between the measured values and the theoretical values.

Assuming that the normal distance between the measured point and the theoretical point is the normal error $\Delta d$, which is used to measure the deviation between two points. According to the following equation [3]:

$$
\Delta d=\left(\vec{R}_{m}^{*}-\vec{R}_{m}\right) \cdot \vec{n}_{m},
$$

where $\vec{R}_{m}^{*}$ is the coordinate value of the measured points, $\vec{R}_{m}$ is the coordinate value of the theoretical points and $\vec{n}_{m}$ is the normal direction of the tooth surface.

The deviation values are obtained by calculating for a real example. The results are shown in the Fig. 12.

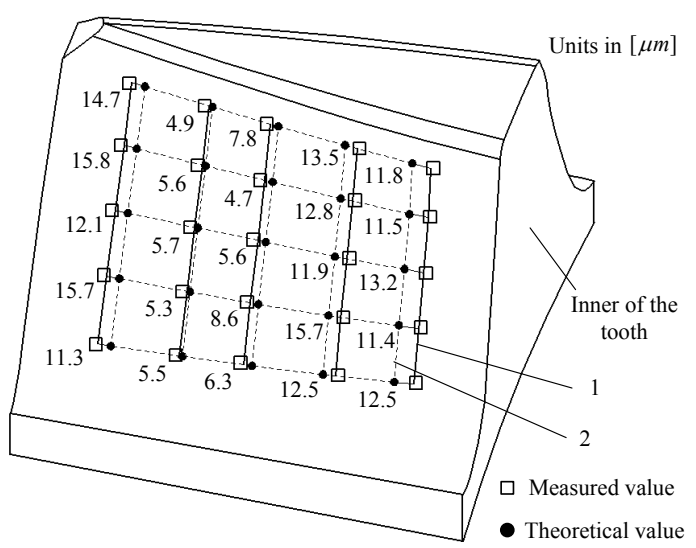

Fig. 12. Error distribution (1 measured value grid, and 2 theoretical value grid)

The normal deviation value is in the range of $5 \mu \mathrm{m}$ to $16 \mu \mathrm{m}$. The precision of the deviation value satisfies the requirements of GB/T 10095.1-2001 precision class grade 6-7, and meets engineering demands. Therefore the numerical method of calculating tooth profiles has been shown to be accurate. 


\section{CONCLUSION}

In the article, a new kind of gear was generated and geometric and mathematical models were established for this gear. A numerical method used to calculate the tooth profile of the non-circular curved face gear was developed. The correctness of the method was examined by an experiment. The results of the performed research allow the following conclusions to be drawn:

a) The relevant parameters of arbitrary curves were calculated in terms of the cylindrical coordinate system. The parametric equations of the pitch curve of the non-circular curved face gear and the normal equidistant curve equation were obtained.

b) The tooth profile of the non-circular curved face gear in the tooth width direction was obtained by changing the point on the tooth profile of the cutter to the coordinate system of the non-circular curved face gear through the method of coordinate conversion and where the intersection with its pitch curve and the normal equidistant curve occurs.

c) The error of the tooth profile between the theoretical calculations and the actual measurements was analyzed. The results showed that using the numerical method to solve the tooth profile of a non-circular curved face gear high precision and good universality. This calculation method will be of service in the field of error analysis of the tooth surface, accuracy assessment of tooth surface and manufacture, and so on.

\section{ACKNOWLEDGEMENTS}

The authors would like to recognize the support of the National Natural Science Foundation of China (51275537) for this research.

\section{REFERENCES}

[1] Hai, G. (2012). Transmission Design and Characteristic Analysis of Orthogonal Non-circular Face Gear Drive. MSc Thesis, Chongqing University, Chongqing, p. 7-24. (in Chinese)
[2] Buckingham, E. (1988). Analytical Mechanics of Gears. Dover Publication, New York, p. 6-32.

[3] Litvin, F.L. Faydor, L. (2004). Gear Geometry and Applied Theory. Cambridge University Press, New York, p. 484-518, Dol:10.1017/СВ09780511547126.

[4] Guanghu, J., Rupeng, Z., Heyun, B. (2010). Nonlinear Dynamical Characteristics of Face Gear Transmission System. Journal of Central South University (Science and Technology), vol. 41, no. 5, p. 1807-1813. (in Chinese)

[5] Chao, L., Shasha, L., Hai, G. (2014). Design and 3D modeling of orthogonal variable transmission ratio face gear. Journal of Hunan University (Natural Sciences), vol. 41, no. 3, p. 49-55, D0I:10.3969/j.issn.1674-2974.2014.03.009. (in Chinese)

[6] Chao, L., Hai, G., Ning, N., Qinlong, Z., Lei, Z. (2013). Geometry design, three-dimensional modeling and kinematic analysis of orthogonal fluctuating gear ratio face gear drive. Proceedings of the Institution of Mechanical Engineers, vol. 227, no. 4, p. 779-793, DOI:10.1177/0954406212453382.

[7] Jiqiang, X., Yuanyuan, L., Chunming, G., Jiangbin, S. (2008). Noncircular bevel gear transmission with intersecting axes. Journal of Mechanical Design, vol. 130, no. 5, p. 054502 , DOI:10.1115/1.2885510.

[8] Jiangang, L., Xutang, W., Shimin, M., Jingliang, H. (2005). Numerical computation of tooth profile of noncircular gear. Journal of Xi'an Jiaotong University, vol. 39, no. 1, p. 75-78. D0I:10.3321/J.issn:0253-987X.2005.01.018. (in Chinese)

[9] Ting, T., Fangyan, Z., Ke, S., Bing, Y. (2013). Non-circular gear teeth profile numeric method based on normal tooth profile. Journal of Wuhan University of Technology (Transportation Science \& Engineering), vol. 37, no. 3, p. 652-654, D0l:10.3963/j.issn.2095-3844.2013.03.048. (in Chinese)

[10] Guenther, A., Kniel, K., Härtig, F., Lindner, I. (2013). Introduction of a new bevel gear measurement standard, CIRP Annals - Manufacturing Technology, vol. 62, no. 1, p. 515-518, Dol:10.1016/j.cirp.2013.03.083.

[11] Guenther, A. (2011). Interpretation of bevel gear topography measurements. CIRP Annals - Manufacturing Technology, vol. 60, no. 1, p. 551-554, D0l:10.1016/j.cirp.2011.03.060.

[12] Jinliang, Z., Zongde, F., Xuemei, C., Xiaozhong, D. (2007). The modified pitch cone design of the hypoid gear: manufacture, stress analysis and experimental tests. Mechanism and Machine Theory, vol. 42, no. 2, p. 147-158, D0l:10.1016/j. mechmachtheory.2006.09.008.

[13] Yanan, W. (2013). Research on Hobbing Method of Face Gear. MSc Thesis, Harbin Institute of Technology, Harbin, p. 13-15. (in Chinese) 